\title{
Quando os(as) alunos(as) já são professores(as): estágio, pesquisa e prática docente na formação de professores(as) indígenas ${ }^{*}$
}

\section{When students become teachers: training period, research and teaching practice in the formation of indigenous teachers}

\author{
Carlos Humberto Alves Corrêa** \\ Elciclei Faria dos Santos*** \\ Rosa Helena Dias da Silva***
}

Resumo: O artigo aborda o tema central do estágio no Curso de Formação de Professores Indígenas da Universidade Federal do Amazonas (UFAM) enquanto um dos principais desafios para a formação de professores indígenas em nível superior. Como os alunos universitários indígenas já são professores(as) em suas aldeias, procurase saber que tipos de atividades caracterizarão este momento formativo e comporão o estágio e como articular as ações de pesquisa e prática docente oportunizando a soma de esforços e produção de resultados que sejam contribuição tanto para a formação do(a) professor(a) como para as escolas indígenas. Também focaliza a experiência já vivida com a Turma Mura, que está no último ano do curso e no fim de seu estágio. O estágio tem sido entendido como um espaço/tempo de reflexão e ação sobre a realidade escolar e o exercício da docência, tendo em vista potencializar a formação dos(as) licenciandos(as) e qualificar as suas inserções profissionais e, consequentemente, o trabalho da escola indígena.

Palavras-chave: Formação de professores indígenas. Estágio. Pesquisa. Prática docente.

Abstract: The main traineeship theme in the Indigenous Teachers Training Course at
the Federal University of Amazonas is one of the most important challenges in the
college training of indigenous teachers. Since indigenous university students are already

* Este artigo articula debates e resultados de dois projetos em desenvolvimento pelo Grupo de Pesquisa "Formação do educador(a) no contexto amazônico": 1) Políticas afirmativas de acesso ao ensino superior: as licenciaturas específicas para formação de professores indígenas nas Instituições de Ensino Superior públicas da Amazônia brasileira (financiamento CNPq - 2007/2009) e 2) A educação escolar Mura: práticas pedagógicas e formação docente (financiamento FAPEAM - 2007/2009), com a reflexão e aprendizados adquiridos pelos autores na Coordenação do Curso de Licenciatura Formação de Professores Indígenas da UFAM e na Coordenação do Estágio.

* Docente da Faculdade de Educação da Universidade Federal do Amazonas. E-mail: <parachac@hotmail.com>

*** Docente da Faculdade de Educação da Universidade Federal do Amazonas. E-mail: <elcicleisantos@hotmail.com>

**** Docente da Faculdade de Educação da Universidade Federal do Amazonas. E-mail: <rhelenamanaus@gmail.com> 
teachers in their villages, current investigation endeavors to answer the following questions: What kind of activities will characterize this training and which will compose the teachers' formation? How may research and teaching practice be articulated so that efforts and results may contribute towards teacher training and indigenous schools? Current research focuses on the experience of the Mura Class which is in its final year and finishing its traineeship. Traineeship has been a space-time opportunity for reflection and activities on the school and on the teaching practice to highlight teachers' training, qualify their professional insertions and, consequently, the work of the indigenous school.

Keywords: Indigenous teachers' training. Traineeship. Research. Teaching practice.

\section{Introdução}

A questão da formação de professores indígenas tem se destacado nos últimos anos no cenário indígena e indigenista, quer enquanto reivindicação do movimento indígena - em especial dos professores - quer enquanto políticas públicas que procuram atender a essa demanda, que se insere no bojo da problemática da oficialização das escolas indígenas.

Tomando como referência os movimentos de professores indígenas na Amazônia, podemos afirmar que há mais de 20 anos os povos indígenas vêm se organizando para fazer valer seu direito a uma escola própria e, consequentemente, o direito a processos de formação docente também próprios.

O Curso de Licenciatura Formação de Professores Indígenas, que vem sendo implantado pela Universidade Federal do Amazonas (UFAM) desde $2008^{1}$, junta-se a outras iniciativas que têm procurado responder a este desafio institucional de contribuir na formação específica de professores indígenas para atuarem nas escolas de suas aldeias. Configura-se como uma possibilidade de ampliação da atuação desta instituição de Ensino Superior (IES) junto aos povos indígenas do Amazonas.

No dia $1^{\circ}$ de maio de 2008 teve início a primeira turma do curso, com 60 alunos do povo Mura, no Município de Autazes/AM. Em 2011 foram implantadas duas novas turmas, sendo uma com 47 alunos do povo Munduruku, no município de Borba/AM, e a outra com o povo Sateré-Mawé, no município de Maués/AM, com 56 alunos².

\footnotetext{
${ }^{1}$ O Curso foi aprovado pelas instâncias superiores da UFAM - Câmara de Ensino de Graduação do Conselho de Ensino, Pesquisa e Extensão (CONSEPE), tendo sido criado pela Resolução 010/2007, de 18/04/07, vinculado à Faculdade de Educação/FACED.

${ }^{2}$ Para dar conta da ampliação da oferta de novas turmas, conforme demandas apresentadas por outros povos indígenas da região, a Resolução 041/2009 (CEP/PROEG) alterou o nome do curso, que passou de "Formação de Professores Indígenas Mura", para "Formação de Professores Indígenas".
} 
A tarefa de construir um curso novo tem representado um grande desafio institucional mas bastante enriquecedor, uma vez que a elaboração do projeto inicial (para atender a turma Mura, iniciada em 2008) e das adequações (para atender as turmas Sateré-Mawé e Munduruku, iniciadas em 2011) se deu conjuntamente, em um processo de protagonismo compartilhado, tendo como principais sujeitos os próprios professores e lideranças indígenas, representados por suas organizações, e os professores da UFAM, coordenados por um grupo de docentes da Faculdade de Educação (FACED).

A implantação do curso representa um novo e importante passo na consolidação da atuação da UFAM na formação de professores indígenas e visa fortalecer seu compromisso institucional com esta realidade, atendendo, até este momento (2012), à reivindicação apresentada pelos povos Mura (região de Autazes/AM), Sateré-Mawé (região de Maués/AM e região de Barreirinha/ AM) e Munduruku (região de Borba/AM e região do Tapajós/PA).

Dentre os inúmeros desafios para a formação de professores indígenas em nível superior, um será tomado aqui como tema central: a problemática do estágio ${ }^{3}$. Como os(as) alunos(as) universitários(as) indígenas já são professores(as) em suas aldeias, era preciso decidir que tipos de atividades caracterizariam este momento formativo e comporiam o estágio e como articular as ações de pesquisa e prática docente oportunizando a soma de esforços e produção de resultados que contribuíssem tanto para a formação do(a) professor(a) como para as escolas.

Procurando coerência teórico-metodológica e pedagógica para atender a um desafio tão complexo e instigador, o curso procura ser espaço que possibilite, ao mesmo tempo, a revitalização dos conhecimentos indígenas e o aperfeiçoamento e a ampliação destes saberes. Seguindo esta perspectiva, o curso coloca ênfase na reflexão sobre a própria prática pedagógica dos professores indígenas, aprimorada e ampliada com a prática de estudo, sistematização e pesquisa.

É para dar conta desta concepção que desenhamos, na matriz curricular, as diretrizes para desenvolvimento do estágio, cujas ideias-chaves nortearão o presente texto. Tomaremos como foco da reflexão aqui proposta a experiência já vivida com a Turma Mura, que está no último ano do Curso e no fim do estágio.

\footnotetext{
${ }^{3}$ Sem esquecer ou ignorar os enormes entraves que ainda se colocam à efetivação de projetos indígenas de escola e sem perder de vista os imensos desafios inerentes aos processos de formação de professores indígenas - problematizações estas que temos desenvolvido em outros textos - importa neste trabalho focalizar como, na implantação e desenvolvimento de um curso de licenciatura específica, tem sido tratado o tema do estágio.
} 


\section{Breve descrição do curso}

O curso, realizado em regime modular, é organizado em turmas de acordo com os povos indígenas. Atualmente ${ }^{4}$ está sendo realizado nos municípios de Autazes (Turma Mura), Borba (Turma Munduruku) e Maués (Turma Sateré-Mawé), em duas etapas intensivas de funcionamento por ano - uma de um mês e uma de dois meses. A turma Mura tem aulas nos meses de maio, outubro e novembro; a turma Munduruku, nos meses de março, agosto e setembro; e a turma Sateré-Mawé, em maio, junho e outubro.

Segundo consta do projeto político-pedagógico do curso (UNIVERSIDADE FEDERAL DO AMAZONAS, 2012, p. 13), seu objetivo geral é

Formar, em nível superior, numa perspectiva intercultural e interdisciplinar, professores indígenas para atuar na $2^{\mathrm{a}}$ etapa do ensino fundamental e no ensino médio, nas escolas indígenas, com habilitação plena nas áreas de Ciências Humanas e Sociais; Ciências Exatas e Biológicas; Letras e Artes.

Os objetivos específicos procuram atender ao desafio de articular a formação dos professores com sua atuação docente na escola indígena e o compromisso de fazer avançarem as propostas indígenas de escola, ou seja, os projetos político-pedagógicos das próprias escolas indígenas na perspectiva da interculturalidade, enquanto partes de uma política identitária mais ampla. São eles:

1) contribuir para o avanço do projeto político-pedagógico das escolas indígenas; 2) oferecer condições para que as escolas indígenas, através do trabalho educativo integrado dos professores e comunidades, possam promover o acesso aos saberes científicos historicamente construídos pela humanidade, bem como a valorização do patrimônio territorial, cultural e ambiental indígena, propiciando um diálogo intercultural, a partir de suas lógicas e valores; 3) possibilitar aos professores indígenas um processo de formação que contribua para a construção de condições de promover em sala de aula o processo educativo que, fundamentado na cultura e forma de pensamento própria de cada povo, possa estar orientado para a melhoria das condições de vida, através da apropriação crítica de bens culturais e recursos tecnológicos advindos de outras sociedades. (UNIVERSIDADE FEDERAL DO AMAZONAS, 2012, p. 13).

Com duração total de cinco anos e carga horária total de 3165 horas $^{5}$, o curso se constitui das seguintes etapas:

\footnotetext{
${ }^{4}$ A UFAM, através de projeto aprovado em 2010 pela SECAD/MEC, construirá, na Fazenda Universitária, em Manaus (KM 39 da BR 174), um Centro de Referência para Formação de Professores Indígenas. Quando o Centro estiver pronto, as aulas passarão a ser ali realizadas.

${ }^{5}$ Divididas entre: I. Formação Geral (1320 horas); II. Formação Específica (840 horas); III. Formação para Integração das Áreas (600 horas, na forma de Práticas como Componente Curricular - 400h e Outras Formas de Atividades Acadêmico-Científico-Culturais 200h) e IV. Estágio - 400h.
} 
- uma etapa de formação geral, com duração de dois anos e carga horária de 1320 horas, para estudo dos fundamentos e noções básicas (disciplinas pedagógicas e das três grandes áreas), com todos os alunos indígenas estudando juntos;

- uma etapa de formação específica, por três (3) grandes áreas: (1) Ciências Humanas e Sociais - História; Geografia; Antropologia; Sociologia; Filosofia. (2) Ciências Exatas e Biológicas - Matemática; Química; Física; Biologia. (3) Letras e Artes - Língua Portuguesa; Língua Indígena; Expressão Cultural e Práticas Corporais. Duração de dois anos e carga horária de 840 horas, para completar o estudo da formação geral e dos conteúdos específicos de cada grande área, de acordo com a opção de cada graduando;

- uma etapa de integração das áreas, com duração de um ano, momento em que todos os alunos indígenas da turma (por povo) juntar-se-ão novamente para discutirem os resultados dos trabalhos de pesquisas, de estágios, a elaboração e reelaboração do Projeto Político-Pedagógico das escolas indígenas, os Trabalhos de Conclusão de Curso e outras questões relevantes que forem surgindo ao longo do Curso. (UNIVERSIDADE FEDERAL DO AMAZONAS, 2012, p. 17).

\section{O estágio para alunos que já são professores}

No âmbito da Licenciatura Formação de Professores Indígenas, o estágio, que se realiza de forma articulada com todas as etapas acima descritas, tem sido entendido como um espaço/tempo de reflexão e ação sobre a realidade escolar e o exercício da docência tendo em vista potencializar a formação dos licenciandos e qualificar a sua inserção na profissão e, consequentemente, o trabalho da escola.

Ao pensarmos o estágio nessa perspectiva, buscamos superar a visão de que o momento do estágio seja a parte prática da formação dos professores, uma espécie de apêndice do currículo da licenciatura (PIMENTA; LIMA, 2005/2006).

Neste conjunto de referências foi necessário construir um entendimento comum (e ampliado/flexível) sobre a noção de estágio no Curso e, a partir desta, elaborar um conjunto de materiais ${ }^{6}$ que fossem capazes de subsidiar as atividades que comporiam a prática do estágio em seus diferentes momentos.

A definição do campo de estágio levou em consideração que a maioria dos alunos já atuam como professores em suas aldeias e que, nos processos de

\footnotetext{
${ }^{6}$ Entre os materiais elaborados até o momento destacamos: Grupo de Supervisão Coletiva: espaço articulador entre ensino/estágio/pesquisa; Sua escola tem história?; Roteiro de Observação e Levantamento I (a sala de aula e o trabalho docente); Roteiro de Observação e Levantamento II (a escola e o seu entorno); Roteiro para elaboração de Plano de Ação.
} 
formação de professores indígenas já estabelecidos - a exemplo dos magistérios indígenas coordenados pelas secretarias estaduais de Educação e das licenciaturas implantadas por algumas universidades - a própria escola onde ele atua tem sido seu lugar de estágio. Neste sentido o estágio será realizado nas próprias escolas indígenas onde os(as) licenciandos atuam como professores. Professores que atuam em escolas que ofereçam apenas a Educação Infantil e/ou do $1^{\circ}$ ao $5^{\circ}$ ano do Ensino Fundamental puderam realizar seus estágios nesses segmentos escolares, embora a licenciatura esteja voltada à formação de professores para atuarem em outras etapas de escolarização; já os professores que atuam em turmas do $6^{\circ}$ ao $9^{\circ}$ ano do Ensino Fundamental e/ou no Ensino Médio desenvolvem suas ações de estágio nesses segmentos escolares.

A Resolução n. ${ }^{\circ} 2$ do Conselho Nacional de Educação (BRASIL, 2002b) estabelece a duração e a carga horária dos cursos de licenciatura, de graduação plena e de formação de professores da Educação Básica em Nível Superior. Nela está estabelecido o mínimo de quatrocentas horas de estágio curricular supervisionado, a serem cursadas a partir do início da segunda metade da integralização dos créditos do curso. Para os professores que já estão em sala de aula a lei reduz essa exigência para duzentas horas de estágio curricular supervisionado.

As reflexões coletivas que temos realizado no Colegiado Ampliado do curso 7 têm nos ajudado a perceber algumas formas de encaminhar as questões relativas ao tempo de estágio. Uma primeira constatação é que as três disciplinas de estágio (Estágio Supervisionado I, II e III) perfazem o total de quatrocentas e cinco horas, das quais cento e trinta e cinco são presenciais e duzentas e setenta são realizadas no campo de estágio.

Os encontros presenciais das disciplinas servem como espaço de orientação, reflexão e discussão coletiva sobre diferentes momentos e sobre as ações a serem desenvolvidas ao longo do estágio. No Estágio Supervisionado I, por exemplo, priorizou-se a discussão das diretrizes gerais do estágio e a orientação sobre a fase de levantamento das necessidades e potencialidades e do diagnóstico da realidade escolar; no Estágio II foram discutidos os levantamentos feitos pelos professores indígenas sobre aspectos da realidade de suas salas de aula e escolas e as dificuldades enfrentadas no desenvolvimento destes levantamentos, bem como a elaboração dos planos de trabalho; e no Estágio III demos atenção ao desenvolvimento e avaliação das ações, assim como à socialização dos resultados e produtos.

\footnotetext{
${ }^{7}$ No dia 28/09/2011, em reunião do Conselho Departamental da Faculdade de Educação, foi aprovada a criação do Colegiado do Curso "Formação de Professores Indígenas", incluindo a Coordenação Ampliada, que conta com a presença de docentes das demais unidades acadêmicas que participam do curso (Instituto de Ciências Humanas e Letras - ICHL, Instituto de Ciências Biológicas - ICB, Instituto de Ciências Exatas - ICE e Faculdade de Educação Física e Fisioterapia - FEFF).
} 
A carga horária no campo de estágio foi destinada ao desenvolvimento de atividades e ações discutidas e encaminhadas nos encontros presenciais. A confecção e entrega dos trabalhos solicitados em cada uma delas resultou na computação das horas de trabalho em campo encaminhadas nas disciplinas Estágio I, II, III.

As horas de participação efetiva nas reuniões e atividades realizadas pelo Grupo de Supervisão Coletiva de Estágio, assunto que detalharemos mais adiante, serão computadas como horas de estágio, desde que atendam aos requisitos exigidos pela coordenadoria do curso. ${ }^{8}$

Os objetivos estabelecidos para o estágio buscaram traduzir a compreensão que conseguimos construir até o momento, fruto das discussões nas reuniões colegiadas do curso, do estudo da bibliografia pertinente ao tema e do conhecimento das experiências de outras licenciaturas específicas. São eles:

- refletir sobre a relação teoria e prática no processo de formação e exercício da docência;

- desenvolver uma postura investigativa sobre o conjunto do espaço escolar e da aldeia;

- elaborar, desenvolver e socializar projetos escolares de ensino-pesquisa relacionados às áreas específicas de formação e atuação;

- investigar a realidade educacional, de modo a contribuir para o trabalho educacional, o trabalho docente e o aperfeiçoamento do projeto políticopedagógico da escola indígena;

- identificar e analisar os problemas cotidianos da escola e da sala de aula onde o estagiário atua, bem como os meios de solucioná-los;

- utilizar o registro escrito para documentar o trabalho pedagógico e para refletir sobre a prática, tendo em vista o seu aperfeiçoamento;

- experimentar situações de ensino-aprendizagem, avaliando suas repercussões no seu cotidiano e no cotidiano da escola/aldeia;

- confeccionar materiais didáticos, metodologias de ensino e/ou de avaliação que sintetizem e potencializem uma pedagogia escolar indígena.

De início, as visitas de acompanhamento estavam previstas como as formas privilegiadas de acompanhar o estágio e as pesquisas dos alunos do

\footnotetext{
${ }^{8}$ Outras possibilidades de contabilização de carga horária para o estágio dizem respeito à participação dos(as) licenciandos(as) nos encontros/visitas de acompanhamento nas escolas indígenas, nas reuniões da Organização dos Professores Indígenas e/ou a participação dos mesmos em encontros/eventos científicos ligados a sua área de formação. Não descartamos a possibilidade de uso dos cadernos de campo como forma de aferir e contabilizar as horas de estágios dos(as) licenciandos(as). Temos incentivado o uso deste recurso como ferramenta de registro e reflexão das experiências e não como um instrumento burocrático de registro das horas de estágio.
} 
curso. No próprio projeto político-pedagógico do curso existe a previsão de que as visitas de acompanhamento do estágio seriam realizadas por conjunto de escolas agrupadas em uma escola polo?. Vale lembrar que as visitas de acompanhamento visam:

- identificar as dificuldades enfrentadas pelos(as) professores(as) em relação ao desenvolvimento de seus projetos escolares/de ensino-pesquisa, bem como os avanços alcançados;

- discutir com os professores as dúvidas e impasses teórico-práticos enfrentados no exercício da docência;

- avaliar as repercussões dos projetos escolares/de ensino-pesquisa no cotidiano da escola/comunidade;

- observar as práticas de ensino desenvolvidas pelos professores Mura; - assessorar os professores no encaminhamento dos seus projetos escolares/de ensino-pesquisa.

Dificuldades de diferentes ordens, especialmente financeiras ${ }^{10}$, têm criado vários obstáculos à realização dessas visitas com a frequência e nos moldes inicialmente planejados. Tendo em vista a compreensão de que o trabalho de acompanhamento do estágio e das pesquisas é condição fundamental no desenvolvimento do curso, temos buscado discutir estratégias de implementação, dinamização e acompanhamento do estágio dos licenciandos indígenas.

Foi nesse contexto de discussão coletiva que, no caso da turma Mura, surgiu a proposta de utilizar as reuniões mensais da Organização dos Professores Indígenas Mura (OPIM) como espaço privilegiado para realizar o trabalho de orientação e acompanhamento do estágio e da pesquisa dos alunos do curso.

\footnotetext{
${ }_{9}^{9}$ No caso da Turma Mura, os pólos foram definidos pela Organização dos Professores Indígenas Mura (OPIM). São eles: Pólo I - Aldeia Trincheira (Cursistas participantes: Escola Trincheira; Escola Indígena Dona Elci; Aldeia Muratuba, Aldeia Sampaio e Aldeia do Padre); Pólo II - Aldeia São Félix (Cursistas participantes: Escola Novo Horizonte; Escola Dr. Jacobina; Escola Capitão Getúlio; Escola Coronel Rondon; Escola Manoel Barroncas; Escola Sete de Setembro; Aldeia Cuia e Aldeia Natal) e Pólo III - Aldeia Murutinga (Cursistas participantes: Escola Manoel Miranda; Escola Novo Sonho e Aldeia do Soares). (UNIVERSIDADE FEDERAL DO AMAZONAS, 2007, p. 19-20).

${ }^{10} \mathrm{O}$ Programa de Apoio à Formação Superior e Licenciaturas Indígenas (Prolind) é ainda hoje a principal via de financiamento que tem oportunizado aos povos indígenas, através das Universidades públicas, a continuidade de seus projetos de formação superior de professores/professoras. Funcionando através de Editais - de forma instável e com prazos previstos para seu fim - o Programa tem gerado incertezas e descontinuidades no que diz respeito à garantia de formação superior dos professores indígenas. Isto tem se dado apesar das reivindicações das Instituições públicas de Ensino Superior que mantém Cursos de Licenciaturas Específicas/Interculturais para que o Prolind deixe de ser um programa e se torne uma política pública permanente. Entendemos assim que a escola indígena - com todas as suas necessidades, incluindo aí, com grande força, a formação de professores - tem o direito de ser pública e plural, oficializada, reconhecida, sem enquadramento, com todos os direitos que a legislação assegura. E que para isso seja realmente garantido, é fundamental a questão do financiamento público.
} 
Avaliamos que a escuta e a leitura dos relatos de cada grupo de escola, assim como a problematização e debate do que foi relatado, são também formas de promover o acompanhamento do estágio e pesquisa de nossos alunos.

O estágio vem sendo desenvolvido por etapas que guardam entre si uma articulação. Ainda que elas possam ocorrer em momentos distintos, é preciso compreendê-las como etapas indissociáveis. Para implementação e dinamização dessas etapas, o Colegiado do Curso propôs aos alunos a criação, em cada escola, do Grupo de Supervisão Coletiva de Estágio ${ }^{11}$. Podemos definir esse grupo como um mecanismo para que os próprios licenciandos possam definir e controlar os seus processos de levantamento, planejamento e intervenções realizados no âmbito do estágio e, ao mesmo tempo, refletir sobre os resultados alcançados no cotidiano das salas de aula e das escolas Mura (UNIVERSIDADE FEDERAL DO AMAZONAS, 2011, p. 1).

A primeira etapa caracteriza-se como momento de levantamento das necessidades e potencialidades da realidade escolar. Trata-se de uma fase de apropriação da realidade para analisá-la e questioná-la criticamente à luz de teorias e de possibilidade de ressignificar as visões e os conhecimentos que se tinham sobre o cotidiano da escola e da sala de aula. É uma fase tradicionalmente reconhecida como um momento de diagnóstico da realidade escolar, quando é feito um mapeamento/levantamento das necessidades e possibilidades da escola; no entanto, quando tratamos de estágio em curso de licenciatura para formação de professores indígenas que já atuam como docentes nas escolas de suas aldeias, é preciso reconhecer que este levantamento da realidade escolar ocorrerá em um contexto em que esses professores atuam e sobre o qual já possuem certo conhecimento.

Como resultado inicial dessa etapa, os alunos foram desafiados a sistematizar seus levantamentos em dois produtos. O primeiro, "Minha escola tem história", configura-se como um material onde grupos de licenciandos, organizados segundo a escola na qual atuam como professores, registrarão as informações relativas à história da escola (como surgiu, como se desenvolveu, transformações que sofreu na estrutura física/pedagógica, pessoas que ajudaram a criá-la e a desenvolver-se, relacionamento com a Secretaria Municipal de Educação e com a comunidade...). Entendemos que o investimento dos professores neste trabalho de composição da história das escolas onde atuam pode servir como um recurso importante no processo de reconhecimento e/ou fortalecimento da identidade da escola e de todos aqueles (alunos, professores,

\footnotetext{
${ }^{11}$ Sua criação é resultante de reflexões e estudos realizados no Colegiado do Curso tendo em vista construir uma proposta articulada de estágio, pesquisa e ensino no Curso de Licenciatura. A proposta de implantação desses grupos foi discutida com os alunos da Turma Mura nas aulas da disciplina Organização do Trabalho Escolar II e contou com a adesão dos mesmos.
} 
comunidade) que de alguma forma participaram e ajudaram a tecer essa história. Além disto, o material produzido a partir dessa atividade significa, de certa forma, uma primeira reaproximação dos licenciandos dos contextos onde atuam e estão realizando os seus estágios.

Para a segunda produção, os licenciandos foram instigados a tomar a escola e as salas de aulas (as suas e de seus colegas) como objetos de observação, tendo como material de apoio dois roteiros: o da escola e o seu entorno e o da dinâmica de sala de aula e do trabalho docente. Vale dizer que a opção pela técnica de observação não exclui a possibilidade de os licenciandos, autonomamente, lançarem mão de outros instrumento/procedimentos de pesquisa neste trabalho de apropriação compreensiva da realidade escolar e da sala de aula.

Para a realização dos dois trabalhos enfatizamos a necessidade de os licenciandos recorrerem ao registro escrito como forma preferencial de documentar a realidade investigada, ainda que outras formas de registro (fotográfico, pictográfico, videográfico) possam ser utilizadas. Os materiais produzidos pelos alunos foram lidos pelos professores de Estágio Supervisionado I e devolvidos aos próprios alunos para servirem como material de apoio ao desenvolvimento das etapas posteriores. Vemos a possibilidade de esses registros servirem de material sobre o qual possamos nos debruçar para refletir e problematizar os processos de observação (observações realizadas) e o próprio objeto observado (as escolas e salas de aula observadas).

A segunda etapa é a de elaboração e planejamento das ações. Esta fase guarda íntima vinculação com o material produzido na fase anterior e implica a tomada de uma série de decisões e o estabelecimento de prioridades. Alguns documentos servem como base de consulta para o planejamento do que será realizado pelos alunos do curso. Entre eles destacamos o Referencial Curricular Nacional para as Escolas Indígenas (RCNEI), o projeto político-pedagógico das escolas indígenas e os registros da fase de observação e levantamento. $\mathrm{O}$ estudo e a reflexão coletiva destes e outros materiais (cadernos de textos trabalhados nas diferentes disciplinas do curso, acervo bibliográfico das escolas e dos licenciandos) também podem auxiliar no momento de decidir e projetar o que e como fazer. As ações podem ser organizadas em forma de projeto (de ensino ou pesquisa) e/ou planos de trabalho e/ou de ação (individuais ou coletivos) ${ }^{12}$.

A terceira etapa é a fase de implementação e avaliação das ações previamente planejadas e expressas nos projetos (de ensino ou pesquisa) e/ou planos de trabalho e/ou de ação (individuais ou coletivos). Vale lembrar que toda ação planejada e organizada carrega certa intencionalidade daquele(s) que

\footnotetext{
${ }^{12}$ Para orientar a confecção desses planos de ação foi sugerido um roteiro.
} 
a pensou(aram) e realizou(aram). No momento de desenvolver as ações é importante buscar documentar os efeitos que estas vão surtindo na sala de aula, na escola e nas pessoas (alunos, pais de alunos, comunidade, colegas professores...).

Além de serem operacionalizadas, as ações precisam ser avaliadas. A adoção de sistemáticas de avaliação pode ajudar os licenciandos nesse processo de dinamicamente refletir sobre suas experiências e intervenções realizadas nas situações de estágio à luz da teoria e dos problemas práticos que enfrentam na escola e na sala de aula. A avaliação dimensiona não apenas os efeitos e ganhos das ações desenvolvidas, mas também a natureza do próprio processo de desenvolvimento das ações.

A quarta etapa refere-se à socialização dos resultados. Corresponde, na matriz curricular do curso, ao momento de integração das áreas, com duração de um ano, em que todos os alunos se juntam para divulgar e discutir os resultados e produtos dos trabalhos de pesquisa e estágio, os trabalhos de conclusão de curso e outras questões relevantes que forem surgindo ao longo do processo. Além do relato oral, exposições de materiais de fotos e vídeos e outros recursos poderão servir de apoio neste momento de divulgação do trabalho realizado pelos diferentes grupos de escola.

Ao final, como Trabalho de Conclusão do Curso (TCC), cada grupo de escolas deverá entregar o seu relatório das ações ${ }^{13}$. Trata-se de um relatório que abrigará, de forma descritiva e reflexivo-avaliativa, a memória das ações acadêmicas, pedagógicas e de pesquisa desenvolvidas individual ou coletivamente.

\section{O estágio e sua articulação com a pesquisa}

Desde o momento de elaboração da proposta do curso tínhamos o entendimento de que é possível articular estágio e pesquisa enquanto dois importantes momentos formativos do curso, entendidos estes como processos que podem andar juntos, com resultados comuns (parciais e finais) que viabilizem intervenções na escola/comunidade-aldeia.

A perspectiva de estágio a partir da qual trabalhamos permite uma maior articulação com as atividades de pesquisa, em vista da noção de pesquisa que temos buscado delinear ao longo do curso, a qual foi em grande parte explicitada em documento síntese de uma das reuniões da Coordenação Ampliada do Cur$\mathrm{so}^{14}$, realizada para tratar do tema da pesquisa e do estágio. Como compreende-

\footnotetext{
${ }^{13}$ Além do Relatório das Ações, o TCC - resultante dos estudos, pesquisas e estágio realizados - poderá se configurar em diferentes formatos, como, por exemplo: elaboração de material didático, sistematização de uma metodologia própria, sistematização das pedagogias indígenas, relatórios de pesquisa, monografia e outros.

${ }^{14}$ A reunião ocorreu no dia 13 de setembro de 2010 e contou com a presença de professores representantes
} 
mos o estágio como um momento de reflexão e ação sobre a realidade escolar e o exercício da docência - e não apenas como um momento de aplicação prática do instrumental técnico e teórico trabalhado nas diferentes disciplinas - a pesquisa assume um papel central tanto no momento de conhecimento/análise dos contextos onde os licenciandos já atuam como professores, quanto no momento de compreensão/problematização desses contextos, visando a determinadas intervenções.

Por intervenção estamos entendendo diferentes práticas docentes (aulas, oficinas, preparação de materiais didáticos, organização de dicionários, confecção de atlas, sistematização de metodologias próprias, participação em atividades em escolas "não indígenas") que podem representar um retorno concreto (do curso/da formação superior) para as escolas/comunidades indígenas, qualificando assim a prática docente.

Lembramos que há espaços na matriz curricular propícios para as atividades de pesquisa e estágio. São exemplos destes espaços as disciplinas de pesquisa (Pesquisa e Cotidiano da Escola Indígena I e II, as disciplinas Pesquisa nas Grandes Áreas e Cotidiano do Professor Indígena I e II), as Oficinas do $5^{\circ}$ ano - da Etapa de Integração das Áreas e o acompanhamento nas aldeias. O desafio é promover de fato um trabalho articulado e com resultados/produtos "casados"/ conectados - que agreguem e potencializem as atividades de pesquisa/estágio (e não dupliquem tarefas e esforços).

Assim, esta articulação permite a ampliação e análise dos contextos onde se realizam os estágios e as atuações profissionais dos licenciandos, revelando-se como possibilidade na complexidade que marca o fenômeno educacional no cotidiano das escolas indígenas.

\section{O Grupo de Supervisão Coletiva de Estágio: alguns resultados já alcançados}

Para implementação e dinamização dessas etapas o Colegiado do Curso propôs aos alunos a criação, em cada escola, do Grupo de Supervisão Coletiva de Estágio. Esta proposta é resultante de reflexões e estudos realizados no Colegiado do Curso com vista a construir uma proposta articulada de estágio, pesquisa e ensino no Curso de Licenciatura.

das diferentes áreas do conhecimento com as quais o curso trabalha. Em função da riqueza das discussões sobre a noção de pesquisa, decidimos tomar a síntese dessa reunião como material de apoio para as reuniões com os demais professores da licenciatura e para o trabalho com os alunos do curso no interior das disciplinas Pesquisa e Cotidiano da Escola Mura II e Estágio Supervisionado I. 
Desde o início do curso temos insistido na ideia de que a composição de grupos de estudo de professores (que são também os alunos da Licenciatura), organizados por escolas ou por áreas disciplinares, poderia enriquecer os seus processos de formação individual e coletiva e, ao mesmo tempo, repercutir nos trabalhos que realizam em suas salas de aula e em suas escolas.

Vários estudos (FALKEMBACH, 2003; CENPEC, 1994; BATISTA, 2005) têm demonstrado que esta concepção encontra respaldo nas práticas e nas realidades onde professores se reúnem em torno de um grupo de estudo.

Em que pese às semelhanças de formato, finalidades e efeitos existentes entre os Grupos de Estudo e os Grupos de Supervisão Coletiva de Estágio, não há como negar que estes últimos guardam certa especificidade em relação aos seus propósitos de acompanhamento e supervisão de estágio.

Podemos definir esses grupos como um mecanismo que permite aos próprios licenciandos definir e controlar os seus processos de levantamento, planejamento e intervenção realizados no âmbito do estágio e, ao mesmo tempo, refletir sobre os resultados alcançados no cotidiano das salas de aula e das escolas Mura. É um espaço de formação autônoma e permanente, individual e coletiva.

Nesse sentido, o Grupo de Supervisão Coletiva de Estágio pode criar um ambiente mais favorável à articulação entre os conhecimentos da realidade e os conhecimentos pedagógicos e disciplinares construídos nas disciplinas cursadas na Licenciatura, as intervenções realizadas na escola e na sala de aula e as reflexões sobre essas intervenções. (SCHÖN, 1988 apud ALARCÃO, 1996, p. 16-17).

Além disso, não se pode negar que esses Grupos se inserem em um conjunto de estratégias imaginadas no âmbito do curso visando à implementação, dinamização e acompanhamento do estágio dos licenciandos.

A proposta de implantação desses grupos foi discutida com os alunos da turma Mura nas aulas da disciplina Organização do Trabalho Escolar $\mathrm{II}^{15} \mathrm{e}$ contou com sua adesão.

A nosso ver, a adesão dos professores e a implantação desses Grupos apresentam um rol de possibilidades para pensar e intervir nas escolas das aldeias. Isso pode ser mais bem dimensionado a partir da leitura de alguns objetivos que orientaram a proposta de criação desses grupos, a saber:

- criar espaços de aprendizagem coletiva, incentivando a prática de encontros para estudar e trocar experiências, dúvidas, preocupações,

\footnotetext{
${ }^{15}$ A disciplina foi realizada no primeiro semestre de 2011 com a seguinte ementa: O planejamento em educação. O processo do planejamento de ensino. Inter-relações entre os componentes do plano de ensino-aprendizagem.
} 
motivações e saberes relacionados ao trabalho docente;

- potencializar a criação e experimentação de materiais didáticos (textos, livros, CDs, jogos, vídeos...) e metodologias de ensino/avaliação referentes ao cotidiano das escolas Mura;

- favorecer o intercâmbio e o trabalho coletivo como fontes essenciais de conhecimento pedagógico;

- ler e discutir textos sobre temas que considerem relevantes para a melhoria da formação e das intervenções em sala de aula e na escola onde atuam;

- refletir sistematicamente sobre as experiências ganhas e as intervenções realizadas nas situações de estágio à luz da teoria e dos problemas práticos que enfrentam na escola e na sala de aula;

- acompanhar sistematicamente o desenvolvimento do estágio em suas escolas;

- elaborar relatórios das ações do Grupo de Supervisão Coletiva, bem como do acompanhamento do estágio.

Em que pese, porém, à adesão dos alunos, a implantação destes grupos nas escolas indígenas e o seu efetivo funcionamento não foram imediatos. Reuniões, conversas e textos foram alguns dos meios utilizados para detalhar esta proposta em termos de seu funcionamento.

Nossa sugestão foi que as reuniões do Grupo de Supervisão Coletiva fossem semanais e realizadas, preferencialmente, em dias e horários regulares que favorecessem a participação da maioria dos licenciandos e, ao mesmo tempo, não prejudicassem o funcionamento regular da escola e do trabalho de sala de aula. Cada reunião teria um coordenador e um secretário, que teriam, respectivamente, as incumbências de coordenar o encontro e registrar a síntese do que fosse nele discutido/deliberado. A utilização de um caderno foi sugerida como forma de documentar as pautas dos encontros, as deliberações e a relação dos presentes.

A pauta das reuniões deveria ser definida antecipadamente e a finalidade dos encontros poderia variar segundo as necessidades e propósitos dos próprios licenciandos. Isso quer dizer que em uma reunião poderia, por exemplo, ser feito o estudo coletivo de um texto, e em outra(s) poderia acontecer a elaboração de um instrumento de avaliação, a discussão de um fato ocorrido na escola ou a socialização e análise de uma intervenção realizada por um professor em sua sala de aula, etc.

Os resultados dos trabalhos das reuniões semanais do Grupo de Supervisão Coletiva serão problematizados nas reuniões mensais da OPIM, a partir de uma síntese escrita elaborada por um relator escolhido mensalmente pelo grupo. 
Vale dizer que nessas reuniões o Grupo de Supervisão Coletiva de Estágio de cada escola faz o relato oral de suas ações e entrega uma síntese escrita desse relato aos professores das disciplinas de Estágio.

Cada grupo de escolas seria responsável pelo planejamento das atividades que pretende realizar tendo em vista as necessidades e urgências e a sua capacidade de implementá-las. Para despertar o potencial criativo de cada grupo sugerimos algumas possibilidades pensadas a partir de nossas experiências e do texto de Mello; Grellet e Dallan (2011, p. 4), a saber:

- composição de grupo de estudo para leitura, análise, interpretação e discussão de textos que versem sobre matérias/temas que auxiliem no desenvolvimento profissional de seus integrantes e no aperfeiçoamento de suas análises e intervenções no cotidiano da escola;

- composição de grupo de estudo para estudarem os seus modos de ensinar, a realidade escolar ou um de seus aspectos;

- observação mútua das aulas dos integrantes seguida de discussão sobre o que foi observado;

- realização de visitas a escolas onde esteja sendo desenvolvida uma experiência bem-sucedida;

- encontro com outros professores de outras escolas para apresentação e discussão de seus projetos de ensino e/ou de pesquisa;

- realização de atividades de ensino com a presença de observador externo;

- realização de pequenos seminários versando sobre assuntos de interesse da escola que possam ser desenvolvidos por alguns dos integrantes do Grupo de Supervisão Coletiva que os dominem;

- realização de oficinas pedagógicas para demonstração e/ou elaboração e discussão de aulas, material didático, metodologia de ensino, instrumento de avaliação, etc.;

- elaboração de projetos pedagógicos;

- realização de debates com base em algum livro/artigo lido ou vídeo assistido;

- projeção de filmes seguida de discussão/reflexão sobre o tema abordado;

- organização de aulas demonstrativas seguidas de momentos de discussão;

- produção de sínteses escritas (com apoio de vídeo e/ou fotos) sobre as experiências desenvolvidas pelo Grupo de Supervisão Coletiva de Estágio com a intenção de socializá-las com os grupos das demais escolas.

Depois deste processo de detalhamento da proposta de funcionamento dos Grupos de Supervisão Coletiva de Estágio a sua efetiva implantação começa a ser realizada em algumas escolas indígenas Mura. Em junho de 2011 os grupos da Escola Trincheira e da Escola Dr. Jacobina começaram a funcionar. Os grupos das outras sete escolas indígenas só entraram em funcionamento após 
os módulos do curso desenvolvidos em outubro e novembro de 2011. Esta diferença entre os tempos de implantação dos grupos das diferentes escolas pode ser compreendida, em boa parte, a partir de elementos políticos, econômicos e socioculturais, que vão configurando um conjunto de limites e possibilidades no que se refere à composição, organização e cadência de trabalho do corpo docente de cada escola.

A falta de iniciativa do corpo docente da escola, a sensação de isolamento e de insegurança, as constantes dúvidas, a falta de tempo e o excesso de trabalho foram alguns dos motivos explicitados por muitos professores para não terem implantado o Grupo de Supervisão Coletiva em suas respectivas escolas.

Em que pese à influência de todas estas variáveis, constatamos que no caso dos grupos das escolas Trincheira e Dr. Jacobina a iniciativa e empenho de alguns de seus professores (que são também docentes mais antigos e lideranças históricas da OPIM) e o alto grau de organização foram aspectos determinantes para que esses grupos passassem a funcionar em junho de 2011.

De acordo com o relato dos professores em reunião de acompanhamento realizada no fim do mês de janeiro de 2012, todas as nove escolas indígenas Mura tinham o Grupo de Supervisão Coletiva de Estágio em funcionamento, embora uma das escolas, até o momento, ainda não tenha apresentado a síntese escrita das reuniões de seu grupo ${ }^{16}$.

Ao lermos as sínteses das reuniões dos Grupos de Supervisão Coletiva de Estágio das diferentes escolas indígenas Mura podemos ter uma ideia mais nítida sobre como estes grupos estão funcionando (o que estão priorizando em seus encontros, como estão trabalhando, com que frequência, etc.).

Vemos que em geral os grupos das diferentes escolas têm priorizado as atividades de leitura e discussão de textos ${ }^{17} \mathrm{com}$ vistas à melhoria da formação de seus integrantes e das ações por eles desenvolvidas no interior da escola e da sala de aula.

Destacam-se ainda os relatos de reuniões onde a produção e/ou reelaboração dos trabalhos das disciplinas Estágio I e II e das disciplinas de Pesquisa nas grandes áreas, entre outras, foram objeto de atenção dos professores Mura.

Em menor escala, aparecem atividades que buscam realizar uma intervenção mais direta no ambiente da escola ${ }^{18}$.

\footnotetext{
${ }^{16}$ Como a Escola Isabel Moreira Barroncas tem apenas uma professora (aluna do curso), optou-se pela junção com a Escola Capitão Getúlio, ficando, assim, oito grupos de Supervisão Coletiva de Estágio.

${ }^{17}$ Estes textos, em grande parte, referem-se aos cadernos de textos de algumas das disciplinas já cursadas durante cuja realização são lidos integralmente ou apenas parte deles. Capítulos de livros e o Referencial Curricular Nacional para as Escolas Indígenas (RCNEI) também foram mencionados.

${ }^{18}$ São exemplos de atividades com esta finalidade: a elaboração de proposta curricular para ser apresentada
} 
Algumas vezes vimos que o trabalho e as atribuições dos estagiários e do Grupo de Supervisão Coletiva de Estágio se fundem e se confundem com o trabalho e as atribuições do corpo docente e da escola. Muitos professores/ professoras passaram a perceber as reuniões promovidas pelas escolas (reuniões de planejamento bimestral, com os pais e a comunidade...) como reuniões do Grupo de Supervisão Coletiva de Estágio. Em certo sentido, esta fusão e confusão são compreensíveis, se considerarmos as proximidades e interseções entre as ações e responsabilidades de estágio dos licenciandos que já atuam como professores/professoras e o trabalho docente de professores/professoras que são estagiários em seus ambientes profissionais; porém alguns dos grupos começam a reconhecer a necessidade de estabelecer alguns contornos para marcar a especificidade de um e outro grupo. Este foi o caso dos professores da Escola Dr. ${ }^{a}$ Jacobina, os quais definiram que nas reuniões das segundas-feiras seriam discutidos somente assuntos relacionados ao funcionamento da escola (planejamento, preenchimento de diários e outros) e nas reuniões das quintas-feiras se trataria de temas relacionados à formação universitária (leitura em grupo, projetos de pesquisa e outros).

Todas estas atividades parecem mostrar nexo com alguns dos objetivos e formas de trabalhos sugeridos na proposta de criação dos grupos, principalmente aquelas relacionadas a:

- criação de espaços de aprendizagem coletiva, incentivando a prática de encontros para estudar e trocar experiências, dúvidas, preocupações, motivações e saberes referentes ao trabalho docente;

- leitura e discussão de textos sobre temas que considerem relevantes para a melhoria da formação e das intervenções em sala de aula e na escola onde atuam;

- composição de grupos de estudo para leitura, análise, interpretação e discussão de textos que versem sobre matérias/temas que auxiliem no desenvolvimento profissional de seus integrantes e no aperfeiçoamento de suas análises e intervenções no cotidiano da escola.

A ênfase nesta forma de trabalhar e nestas finalidades, em preferência a tantas outras indicadas no documento que apresentava a proposta de criação dos Grupos de Supervisão Coletiva de Estágio, deve-se em grande parte ao fato de, nesse momento, estas atenderem às expectativas mais imediatas dos licenciandos. Não obstante, temos ressaltado a necessidade de os grupos explorarem as outras dinâmicas e os outros propósitos de trabalho até então não contemplados. No interior de alguns grupos já começam a surgir este desejo de realizar

aos professores do Curso para discussão e melhoramentos e a retomada da elaboração do regimento da escola. 
outras atividades, como atesta o trecho da síntese de uma das reuniões da Escola Professora Elcy de Almeida Prado (2012): "Através desses encontros podemos verificar o potencial de cada acadêmico em sua devida área de conhecimento. Pretendemos, nos próximos encontros, fazer simulações de aulas."

Quanto à frequência de trabalho, as sínteses das reuniões indicam uma variação significativa entre os grupos de supervisão coletiva, seja em termos de quantidade seja no tocante à duração dos encontros realizados em cada escola. Vemos nessas sínteses que a Escola Trincheira realizou um total de 39 encontros entre junho de 2011 e fevereiro de 2012. Em média, seus encontros tiveram duração de duas a três horas e foram realizados sempre no período noturno. Já o grupo da Escola Dr. ${ }^{a}$ Jacobina, que também começou a se reunir em junho de 2011, realizou dez encontros até fevereiro de 2012, sendo que metade deles ocorreu em janeiro de 2012. Analisando apenas os registros dos encontros que informaram o horário de início e término das reuniões, percebemos que estas duravam em torno de duas a duas horas e meia e ocorriam nos finais de tarde, logo após o término das aulas. O número de encontros promovidos pelos grupos das outras escolas foram os seguintes: Escola Profa. ${ }^{a}$ Elcy, onze; Escola Manoel Miranda, oito; Escola Novo Horizonte, seis; Escola Sete de Setembro, cinco; e a Escola Capitão Getúlio junto com a Escola Isabel Barroncas, cinco. Em razão da demora na implantação e funcionamento dos respectivos grupos, nestas escolas, todas as reuniões concentraram-se entre o final do mês de dezembro de 2011 e início do mês de fevereiro de 2012. A existência de luz elétrica ou gerador de energia na aldeia, turnos de funcionamento da escola, a distância entre a escola e a casa dos professores e o regime de trabalho do professor são algumas das variáveis que definem o período do dia em que as reuniões dos grupos ocorrerão. Com isto, temos grupos se reunindo no intervalo de almoço, durante a tarde inteira ou apenas no final dela e no período noturno.

\section{Registros do processo e esperanças}

As ações dos professores indígenas no campo de estágio vêm sendo registradas através de instrumentos que se apoiam na língua escrita (caderno de estágio, diários de campo, diário de classe, relatórios, planos de ensino, sínteses dos trabalhos do Grupo de Supervisão Coletiva de Estágio...) e/ ou em outras formas de registro (vídeos, desenhos, fotos...). Segundo os Referenciais para Formação de Professores Indígenas (BRASIL, 2002a, p. 46),

Essas práticas pedagógicas, uma vez explicitadas, narradas e pensadas por seus atores, ocupam importante e especial lugar na formação dos professores indígenas. Por meio desses registros, podem documentar para si e para os 
outros o seu "saber fazer" pedagógico e, ao mesmo tempo, planejar e avaliar, de forma mais intencional e consciente, as atividades cotidianas na escola e na comunidade.

Assim, elas servem para documentar as ações, impressões e reflexões dos professores, ajudando-os a refletir sobre as práticas reais da escola onde atuam, ou seja, seus problemas, avanços e possibilidades.

Ao escrever seu relato do dia [...], qualquer que seja o nome desse ato, o professor dá seguimento a sua formação profissional, aumenta sua a competência de registro e planejamento, bem como de pensamento reflexivo, pensando sobre o que fez naquele dia e o que pode fazer no seguinte. Registra, assim, dados quantitativos e qualitativos sobre o número de alunos presentes, matéria e conteúdo trabalhados, procedimentos e atividades utilizadas, assim como os problemas de aprendizagem observados, etc. (BRASILa, 2002, p. 51).

Por meio do registro escrito é possível ao licenciando documentar o trabalho realizado, anotar observações, controlar o desenvolvimento do trabalho em função do planejamento, anotar dificuldades e soluções para problemas identificados, avaliar as atividades, os materiais e as formas de ensinar, ter material de consulta para elaborar relatórios de trabalho, etc.

Por meio do registro escrito o professor poderá: documentar os conhecimentos adquiridos, dúvidas, sínteses, relatos da prática pedagógica e questões para discussão coletiva; refletir sobre o processo pessoal de aprendizagem e sobre a prática pedagógica; recuperar o que foi aprendido e projetar novas aprendizagens; dialogar com as próprias representações, modificando-as gradativamente quando for o caso; refletir para buscar explicações e soluções para os problemas didáticos; documentar e socializar as experiências vividas; e criar meios para melhor organizar as suas rotinas de ensino.

Além de todas as vantagens e benefícios aqui indicados, os registros de campo, depois de analisados e revisados, irão compor o relatório descritivo e reflexivo das ações acadêmicas, pedagógicas e de pesquisa desenvolvidas individual e coletivamente pelos alunos do curso.

Sinais desta proposta de estágio articulado com a pesquisa e centrado no Grupo de Supervisão Coletiva se manifestam desigualmente nas escolas indígenas Mura, por isso estes sinais ainda são ambíguos e imprecisos em relação aos seus alcances e repercussões na formação e prática dos professores. Não obstante, sinais emitidos nas sínteses de alguns grupos nos enchem de esperança de que a nossa proposta de estágio aqui descrita possa promover experiências significativas de formação:

[...] como é importante essa reunião do grupo de supervisão coletiva de estágio, porque nós não reunimos antes, temos que continuar com a reunião 
do nosso grupo mesmo terminando os nossos estudos na faculdade, a nossa intenção é continuar [...]

[...] estes dias que nós estudamos as apostilas foram importantíssimos para nossos conhecimentos como professoras. [...] comentamos entre nós sobre o tempo que perdemos sem ter lido as apostilas das disciplinas que estudamos em anos anteriores. Foi ótimo ter participado dos dias de reunião do grupo de supervisão (ESCOLA INDÍGENA SETE DE SETEMBRO, 2012).

Sem esquecer ou ignorar os enormes entraves que ainda se colocam à efetivação de projetos indígenas de escola e sem perder de vista os imensos desafios inerentes aos processos de formação de professores indígenas (problematizações estas que temos desenvolvido em outros textos ${ }^{19}$ ), importou neste trabalho focalizar como tem sido trabalhado o estágio na implantação e desenvolvimento de um curso de licenciatura específica para formação de professores indígenas no qual a grande maioria dos alunos já são professores em suas aldeias. Esperamos, ao socializar estas reflexões, que a experiência da UFAM possa dialogar com as demais e assim possibilitar o avanço conjunto de políticas e ações que deem conta dos anseios dos povos indígenas no que se refere aos seus projetos de escola.

\section{Referências}

ALARCÃO, I. Reflexão crítica sobre o pensamento de D. Schön e os programas de formação de professores. In:__ (Org.). Formação reflexiva de professores: estratégias de supervisão. Porto: Porto, 1996. p. 9-39.

BATISTA, A. G. Como estudar e utilizar a coleção? In:__. Organização da alfabetização no ensino fundamental de 9 anos. Belo Horizonte: Ceale/FaE/UFMG, 2005. p. 18-37.

BRASIL. Ministério da Educação. Referenciais para a formação de professores indígenas. Brasília: Secretaria de Educação Fundamental, 2002a.

Resolução CNE/CP n. 2, de 19 de fevereiro de 2002. Institui a duração e a carga horária dos cursos de licenciatura, de graduação plena, de formação de professores da Educação Básica em nível superior. Diário Oficial da União, Brasília, 4 mar. 2002b. Seção 1. p. 9.

CENPEC. Raízes e asas: trabalho coletivo na escola. São Paulo: CENPEC, 1994. v. 3.

\footnotetext{
${ }^{19}$ Destacamos aqui: SILVA, R. H. D. Inclusão e políticas afirmativas em educação para um Brasil pluricultural: reflexões sobre povos indígenas e ensino superior. Educação, Porto Alegre, v. 1, p. 93-107, 2007; SILVA, R. H. D.; HORTA, J. Licenciaturas específicas para formação de professores indígenas nas instituições de ensino superior públicas da Amazônia brasileira: participação e protagonismo compartilhado. Currículo sem Fronteiras, v. 10, p. 182-194, 2010; SILVA, R. H. D.; MORAES, A. A. A.; SANTOS, E. F. Professores(as) indígenas Mura: entre práticas de ensino, processos de formação e estratégias de resistência. In: LINHARES, C.; GARCIA, R. L.; CORREA, C. H. A. (Orgs.). Cotidiano e formação de professores. Brasília: Liber Livro; Manaus: Editora da Universidade Federal do Amazonas, 2011. p. 117-139.
} 
ESCOLA INDÍGENA PROFESSORA ELCY DE ALMEIDA PRADO. Síntese das reuniões de trabalho do Grupo de Supervisão Coletiva de Estágio. Autazes, AM, 2012. Manuscrito.

ESCOLA INDÍGENA SETE DE SETEMBRO. Síntese das reuniões de trabalho do Grupo de Supervisão Coletiva de Estágio. Autazes, AM, 2012. Manuscrito.

FALKEMBACH, E. M. F. Planejamento participativo: uma maneira de pensá-lo e encaminhálo com base na escola. In: VEIGA, I. P. A. (Org.). Projeto político pedagógico da escola: uma construção possível. 16. ed. Campinas: Papirus, 2003. p. 131-141.

MELLO, G. N. de.; GRELLET, V.; DALLAN, M. Formação continuada de professores. Disponível em: <http://www.namodemello.com.br/pdf/escritos/oficio/educontinuada. pdf $>$. Acesso em: 28 out. 2011.

PIMENTA, S. G.; LIMA, M. S. L. Estágio e docência: diferentes concepções. Revista Poíesis, Rio de Janeiro, v. 3, n. 3-4, p. 5-24, 2005/2006.

UNIVERSIDADE FEDERAL DO AMAZONAS. Projeto do curso de licenciatura específica para formação de professores indígenas Mura/ Autazes - Am. Manaus, 2007.

. Projeto de apoio ao desenvolvimento do curso de licenciatura específica para formação de professores indígenas Mura/ Autazes - Am. Manaus, 2008.

Pró-Reitoria de Ensino de Graduação. Faculdade de Educação. Projeto PolíticoPedagógico do Curso de Licenciatura para Formação de Professores Indígenas. Manaus, 2012.

. Faculdade de Educação. Colegiado Ampliado do Curso de Licenciatura Formação de Professores Indígenas/Grupo de Pesquisa Formação de Educadores(as) no Contexto Amazônico (FECAm). Grupo de Supervisão Coletiva: espaço articulador entre ensino/ estágio/pesquisa. Manaus, 2011. 